Anatomia comparativa:

\title{
contribuições da arte para o ensino-aprendizagem na medicina
}

\author{
Comparative anatomy: art contributions to the teaching-learning in medicine
}

Anatomía comparativa: contribuciones del arte a la enseñanza-aprendizaje en la medicina

\author{
Catia Helena de Almeida Lima Massari ${ }^{1}$ \\ Adriano Ferreira Silva ${ }^{2}$ \\ Tais Harumi de Castro Sasahara ${ }^{3}$ \\ Maria Angélica Miglino ${ }^{4}$
}

Resumo: A Anatomia Comparativa estabelece comparações entre os aspectos anatômicos de diferentes espécies animais. Esta pesquisa objetivou investigar como a Anatomia se relaciona tanto com a Medicina quanto com a Arte, além de fornecer informações sobre a influência da anatomia animal sobre o estudo da anatomia humana. Realizou-se uma pesquisa qualitativa, tendo como amostra ilustrações de Leonardo da Vinci e Andreas Vesalius. Os resultados indicaram evidências do estudo do complexo forma-função de animais domésticos e silvestres sobre o ensino-aprendizagem do corpo humano. Conclui-se que estabelecer comparações entre características anatômicas do homem e da mulher com aquelas correspondentes de animais foi importante durante muitos anos e seus efeitos para a Educação Médica ao longo dos séculos podem ser esclarecidos através da Arte.

Palavras-chave: Ciências morfológicas; educação médica; anatomia artística; animais.

\begin{abstract}
Comparative Anatomy establishes comparisons between the anatomical aspects of different animal species. This research aimed at investigating how Anatomy is related to both Medicine and Art, in addition to providing information on the influence of animal anatomy on the study of human anatomy. A qualitative research was carried out, using illustrations by Leonardo da Vinci and Andreas Vesalius as sample. The results indicated evidence from the study of the form-function complex of domestic and wild animals on the teaching-learning of the human body. It is concluded that establishing comparisons between anatomical characteristics of men and women with those corresponding to animals was important for many years and its effects on Medical Education over the centuries can be clarified through the Art.

Keywords: Morphological sciences; medical education; artistic anatomy; animals.
\end{abstract}

Resumen: La Anatomía Comparada hace comparaciones entre los aspectos anatómicos de diferentes especies animales. Esta investigación tuvo como objetivo investigar cómo la Anatomía se relaciona tanto con la Medicina como con el Arte, además de brindar información sobre la influencia de la anatomía animal en el estudio de la anatomía humana. Se realizó una investigación cualitativa, tomando como muestra ilustraciones de Leonardo da Vinci y Andreas Vesalius. Los resultados indicaron evidencia del estudio del complejo forma-función de animales domésticos y salvajes sobre la enseñanza-aprendizaje del cuerpo humano. Se concluye que establecer comparaciones entre las características anatómicas de hombres y mujeres con las correspondientes a los animales fue importante durante muchos años y sus efectos en la Educación Médica a lo largo de los siglos se pueden esclarecer a través del Arte.

Palabras-clave: Ciencias morfológicas; educación médica; anatomía artística; animales.

\footnotetext{
${ }^{1}$ Médica Veterinária Ph.D., Departamento de Cirurgia, Faculdade de Medicina Veterinária e Zootecnia, Universidade de São Paulo (FMVZ/USP), São Paulo, Brasil.

${ }^{2}$ Médico radiologista Ph.D., Hospital Universitário, Universidade de São Paulo (HU/USP), São Paulo, Brasil.

${ }^{3}$ Médica Veterinária Ph.D., Departamento de Cirurgia, Faculdade de Medicina Veterinária e Zootecnia, Universidade de São Paulo (FMVZ/USP), São Paulo, Brasil

${ }^{4}$ Médica Veterinária Ph.D., Departamento de Cirurgia, Faculdade de Medicina Veterinária e Zootecnia, Universidade de São Paulo (FMVZ/USP), São Paulo, Brasil.
} 


\section{Introdução}

A Anatomia Comparativa, como o nome indica, estabelece comparações entre os aspectos anatômicos de diferentes espécies animais. Ela tem sido, algumas vezes, designada de Anatomia Comparada, no entanto este termo é inapropriado, pois comparativo é o que serve para comparar (o que emprega a comparação) enquanto comparado é aquilo que foi contraposto ${ }^{5}$.

Sabe-se que, desde a pré-história, o ser humano já tinha curiosidade de observar e examinar o corpo, tendo notado que havia partes duras e outras moles ${ }^{6}$. Evidências de que o homem pré-histórico tinha interesse pela Morfologia permaneceram na forma de pinturas rupestres encontradas em paredes de cavernas na Europa ${ }^{7,8}$.

$\mathrm{Na}$ Idade Antiga, as observações sobre forma e estrutura do corpo avançaram graças aos egípcios com suas técnicas de mumificação e, posteriormente, aos mesopotâmicos. Na Grécia, o estudo da Anatomia avançou consideravelmente em Alexandria com Herófilo e Erasístrato; posteriormente, um famoso médico grego de Crotona, Acméon, fez as primeiras dissecações do corpo humano. No século V a.C., Aristóteles compilou os estudos de Morfologia realizados no Liceu na obra Historia Animalium com descrições de espécies animais existentes na Grécia e na Ásia Menor. No século II d.C., Cláudio Galeno dissecou porcos, macacos e outros animais, cometendo erros inevitáveis ao transpor seus achados ao modelo humano. A partir então do ano 150 a.C., com o surgimento da Igreja Católica, a dissecação foi proibida por motivos teológicos e então as descrições feitas por Galeno permaneceram inquestionavelmente aceitas por muitos séculos ${ }^{9,10}$.

Assim, na Idade Média, o estudo de Anatomia foi restrito aos clérigos no interior de algumas catedrais (daí o termo "estudo catedrático"). Depois, com o Renascimento, sugiram os ateliês-escolas de Anatomia com grandes artistas que aproximaram a Anatomia da Arte ${ }^{11,12}$.

\footnotetext{
${ }^{5}$ Liberato Di Dio. Tratado de anatomia aplicada. (São Paulo: Poluss 1998).

${ }^{6}$ José Roberto Ortale. "A importância da anatomia na formação do médico." Títulos não-correntes 8, 1/2 (2012), http://periodicos.puc-campinas.edu.br/seer/index.php/bioikos/article/viewFile/971/948

${ }^{7}$ Inés Domingo et al. "Humanizing european paleolithic art: A new visual evidence of human/bird interactions at L'Hort de la Boquera site (Margalef de Montsant, Tarragona, Spain)." L'Anthropologie 123, 1 (2019): 1-18, https://doi.org/10.1016/j.anthro.2019.01.001

${ }^{8}$ Diego Garate et al. "The cave of Atxurra: a new major Magdalenian rock art sanctuary in Northern Spain." Journal of Archaeological Science: Reports 29 (2020): 102120, Doi: https://doi.org/10.1016/j.jasrep.2019.102120

${ }^{5}$ Sanjib Kumar Ghosh. "Human cadaveric dissection: a historical account from ancient Greece to the modern era." Anatomy \& cell biology 48, 3 (2015): 153, http://dx.doi.org/10.5115/acb.2015.48.3.153

${ }^{10}$ Annastasia Conner. "Galen's Analogy: Animal Experimentation and Anatomy in the Second Century CE." Anthós 8 , 1 (2017): 9, https://doi.org/10.15760/anthos.2017.118

11 Won Jin Park et al. "Anatomy in Michelangelo Art." Keimyung Medical Journal 37, 2 (2018): 76-81, http://doi.org/10.0000/kmj.2018.37.2.76

${ }^{12}$ Vasileios Mitrousias et al. "Art \& anatomy: an everlasting relationship creating new insights in teaching surface anatomy." MedEdPublish 9 (2020), https://doi.org/10.15694/mep.2020.000023.1
} 
Esta pesquisa objetiva investigar como a Anatomia se relaciona tanto com a Medicina (humana e veterinária) quanto com a Arte, sendo considerada ciência e técnica artística visual por meio de ilustrações de dois autores renascentistas: Leonardo da Vinci e Andreas Vesalius, além de fornecer informações mais detalhadas sobre o seguinte problema: os dados de anatomia animal influenciaram o estudo da anatomia humana?

\section{Materiais e método}

Realizou-se uma pesquisa qualitativa no Programa de Pós-Graduação em Anatomia dos Animais Domésticos e Silvestres da Faculdade de Medicina Veterinária e Zootecnia da Universidade de São Paulo (FMVZ/USP), adotando-se imagens como documentos de pesquisa ${ }^{13}$. A amostra compreendeu 32 ilustrações de da Vinci e Vesalius, quais foram analisadas a fim de encontrar significados e razões subjacentes dos sujeitos nos detalhes de suas respectivas gravuras ${ }^{14,15,16}$.

O critério de seleção das ilustrações foi a observação da macroscopia dos corpos ilustrados pelos seguintes dois autores: a) Leonardo da Vinci (1452-1519) participou de dissecações e produziu múltiplos esboços de suas descobertas, através de desenhos precisos e com qualidade, por vezes, tridimensional; b) Andreas Vesalius (Wesel) (1514-1564), médico belga de Bruxelas, considerado o pai da anatomia moderna, realizou exímias dissecações durante o seu período como professor de Medicina em Pádua, tendo representado o corpo humano por meio de placas anatômicas preparadas pelo pintor barroco Pietro da Cortona (1596-1669). A escolha das obras deu-se pela marcada influência renascentista, de onde vem o interesse pelo saber científico, sobretudo de Anatomia. Assim, as ilustrações presentes em Os Cadernos Anatômicos de Leonardo da Vinci e De Humani Corporis Fabrica foram analisadas sob a óptica do "como" constituíram as bases da anatomia comparativa ao evidenciar semelhanças e diferenças entre as espécies de mamíferos.

\footnotetext{
${ }^{13}$ Martin W Bauer, George Gaskell. Pesquisa qualitativa com texto, imagem e som: um manual prático. (Petrópolis: Editora Vozes Limitada, 2017).

14 , Charles Donald O'Malley et al. Leonardo da Vinci on the human body: The anatomical, physiological, and embryological drawings of Leonardo da Vinci: with translations, emendations and a biographical introduction. (Bexley: Gramercy Books, 1982).

${ }^{15}$ Frank Zöllner, Johannes Nathan. Leonardo da Vinci, 1452-1519: The Complete Paintings and Drawings, catalogue raisonné. (Colônia: Taschen, 2015).

${ }^{16}$ Charles O’Malley, J. B. C. Saunders. "Andreas Vesalius de Bruxelas, De humani corporis fabrica. Epitome. Tabulae sex: ilustrações e comentários dos trabalhos anatômicos." (Campinas: Editora Unicamp, 2002).
} 


\section{Resultados e discussão}

Leonardo da Vinci foi um dos pioneiros a representar secções transversais de material anatômico. Sua ideia inicial, segundo o pintor, arquiteto e biógrafo italiano Giorgio Vasari (1511-1574), era produzir um tratado de anatomia humana com o professor italiano de Anatomia da Universidade de Pádua Marcantonio della Torre; entretanto este projeto não se concretizou. Seus cadernos foram relativamente esquecidos nas bibliotecas Ambrosiana de Milão e Real de Windsor (Inglaterra) até aproximadamente 1872, quando foram realizados estudos pelos italianos Gaetano Milanesi e Gustavo Uzielli. A primeira exposição deste material foi realizada em 1870 na galeria Grosvenor, em Londres. Certamente, se este tratado fosse publicado, teria revolucionado a anatomia e a fisiologia na época (figuras 1 a 6 ).

A figura 1 evidencia o aspecto morfológico da parte distal do membro pélvico de um urso em diferentes vistas anatômicas. Nota-se a acurácia na representação dos ligamentos tarsometatarsais e dos tendões flexores e extensores dos dígitos, o que corrobora as similaridades com a anatomia do pé humano uma vez que ambas as espécies são plantígradas.

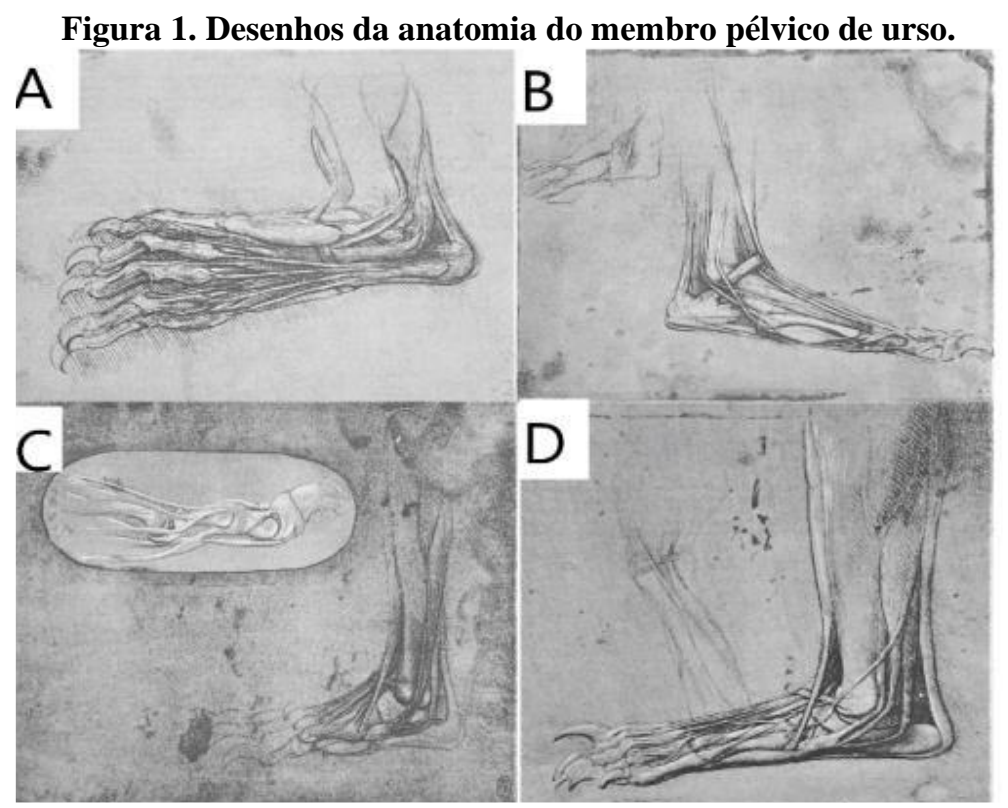

Fonte: O'Malley, Saunders e Saunders (1982).

Já a figura 2 evidencia (em A) a anatomia da asa de uma ave. Da Vinci possuía um verdadeiro fascínio pelos mecanismos que levariam ao voo, tentando ele mesmo inventar máquinas voadoras que tinham por princípio o mecanismo de uma asa (em B). 
Figura 2. Desenhos da anatomia da asa de ave (A) e de um projeto de máquina voadora (B).

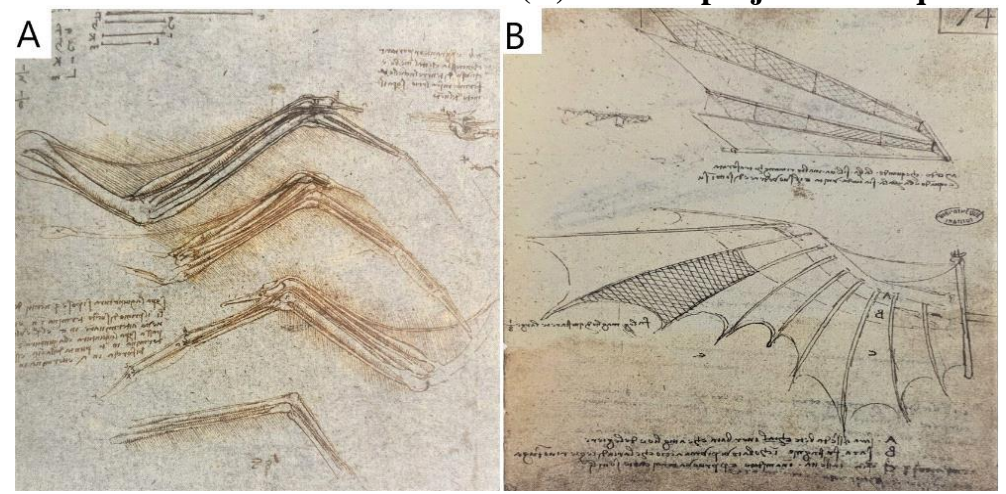

Fonte: Nathan e Zollner (2015).

A figura 3 representa a morfologia do coração de bovino em diferentes vistas anatômicas, onde se nota a representação da circulação coronária. Da Vinci o escolheu como modelo de coração humano por sua similaridade.

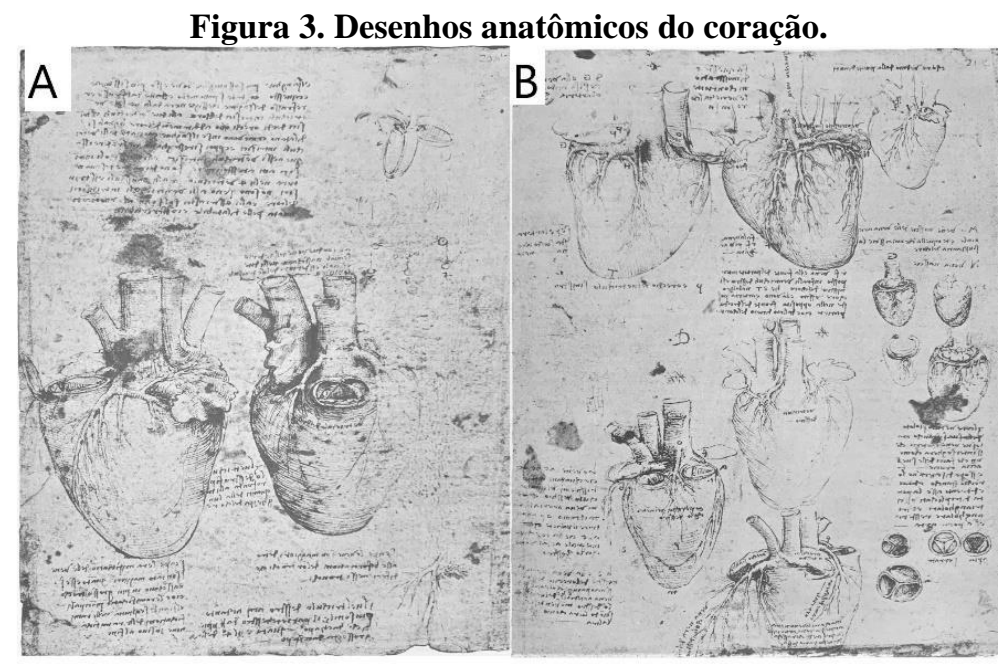

Fonte: O'Malley, Saunders e Saunders (1982).

A figura 4 representa o sistema genital da mulher (A), embora apresente diversas características do uso da anatomia animal. Destaca-se em B (detalhe de A), a disposição dos vasos do arco aórtico que, embora possa ser encontrada em humanos, é típica dos macacos (setas brancas). No coração, apenas duas câmaras foram representadas (uma concepção galênica que considerava os átrios como sendo veias), com a presença de trabéculas septomarginais em ambos os ventrículos ("bandas moderadoras" - setas pretas), indicando a utilização de coração bovino como modelo anatômico. 
Figura 4. Desenho anatômico das estruturas do tórax, abdome e pelve de mulher. B: pormenor de A.

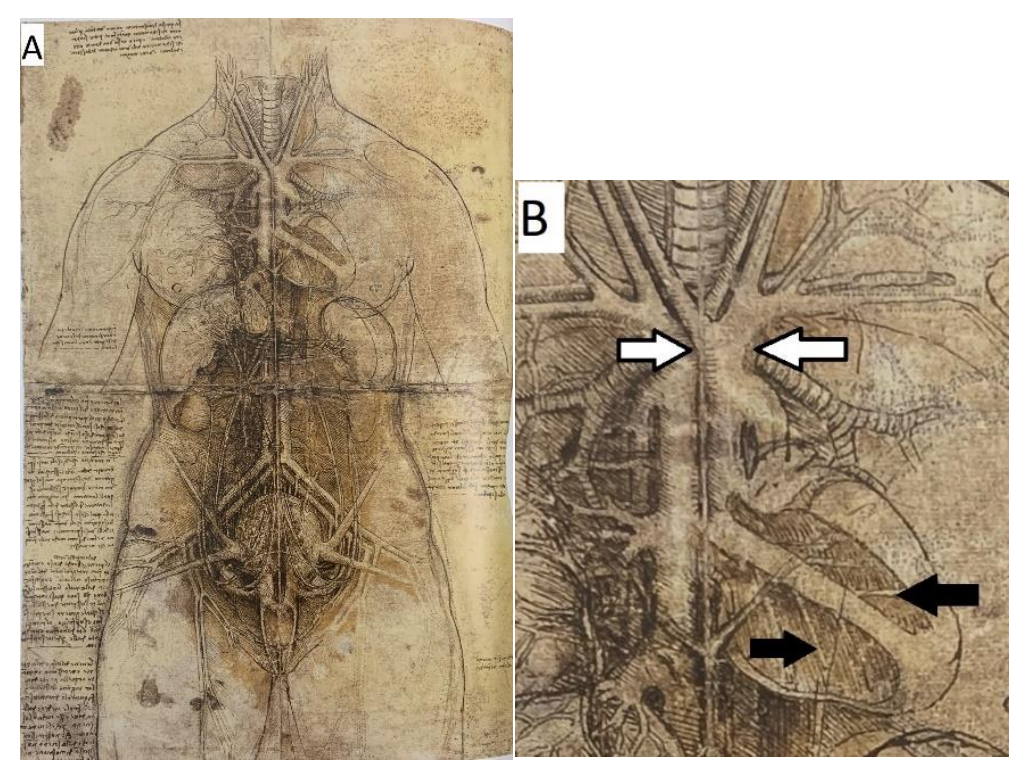

Fonte: Modificado de Nathan e Zollner (2015).

A figura 5 representa o encéfalo humano. Da Vinci foi pioneiro ao injetar cera no interior dos ventrículos cerebrais (detalhe no desenho superior esquerdo e inferior direito), antecipando por séculos a técnica anatômica de injeção de substâncias sintéticas em cavidades e no interior dos vasos, popularizada pelo anatomista holandês Fredrerik Ruysch (1638-1731). Entretanto, ele representa a rete mirabile (um plexo de vasos sanguíneos na base do crânio dos ruminantes, mais evidente em bezerros) - seta - como estando presente no homem. A teoria galênica acreditava que esta rede transformava o "espírito vital” contido nas artérias em "espírito animal” ou "pneuma psíquica”, responsável pelas informações sensitivas e motoras, que seria distribuído pelo sistema nervoso (portanto, os nervos teriam que ser ocos para esse propósito). 
Figura 5. Desenhos anatômicos do encéfalo.

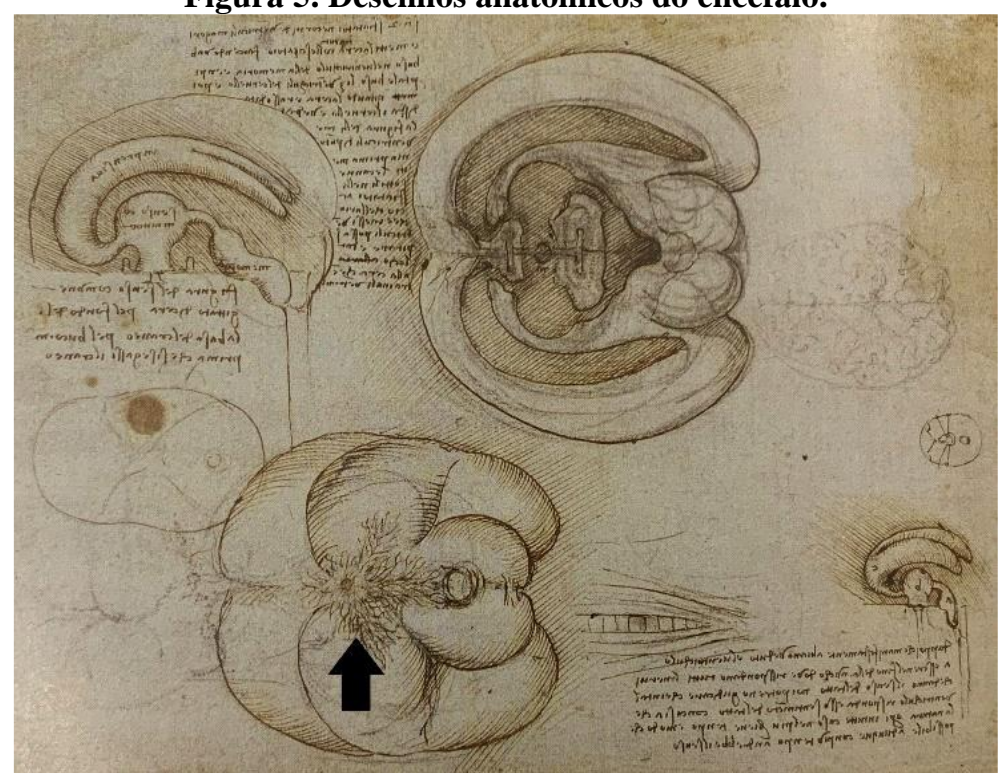

Fonte: Modificado de Nathan e Zollner (2015).

Na figura 6, observa-se uma das primeiras e talvez a mais impressionante ilustração de um feto no interior do útero. Da Vinci consegue representar com extrema tridimensionalidade a posição fetal. Entretanto, ele ainda foi obrigado a se utilizar da anatomia animal em seus estudos, ao representar a placenta cotiledonária dos ruminantes, constituindo os placentomas, ou seja, cotilédones placentários junto às carúnculas uterinas encontradas em vacas - setas em A e representada em sua integridade em B.

Figura 6. A) Desenhos anatômicos de um feto humano no interior do útero e suas membranas fetais. B) Desenhos anatômicos da placenta.

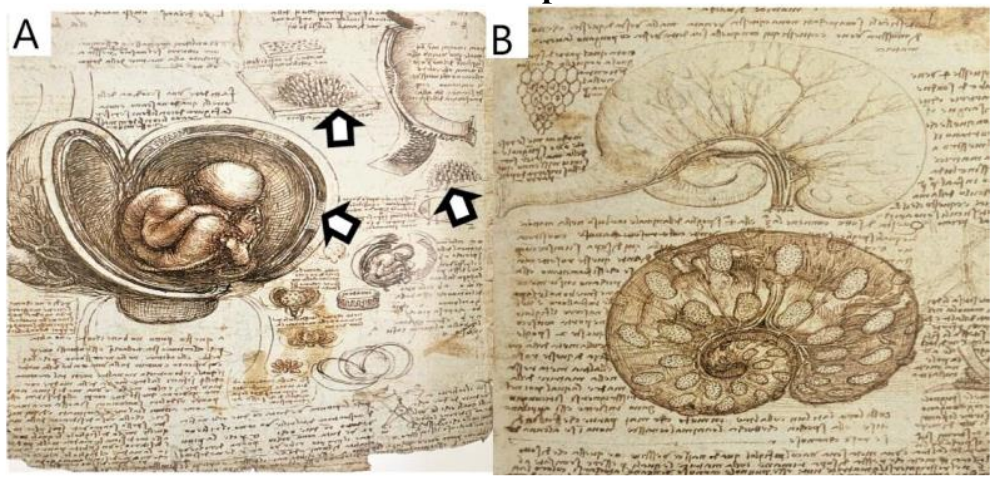

Fonte: Modificado de Nathan e Zollner (2015).

Andreas Vesalius (Wesel), por sua vez, publicou um dos maiores tesouros da civilização e cultura ocidentais: o livro De Humani Corporis Fabrica, e o Epitome, que o sucedeu, em 1543, com ilustrações impressas pelo suíço Joannes Oporinus (1507-1560), através da técnica de xilogravura. A autoria das ilustrações permanece controversa, mas diversas pesquisas apontam o pintor alemão Jan 
Stefan van Kalkar (1499-1546), aluno do pintor italiano Ticiano (cerca de 1476/1490-1576). De Humani Corporis Fabrica é considerado o primeiro tratado de anatomia moderna, não somente pela qualidade pioneira naturalista de suas ilustrações, mas também por incorporar os achados científicos descobertos por Vesalius na época, muitos deles contestando os preceitos do médico e filósofo grecoromano Claudio Galeno (Claudius Galenus, 129-217 d.C.) (figuras 7 a 16).

A figura 7 mostra que já na folha de rosto que representa uma dissecação anatômica pública, Vesalius (seta) inclui os desenhos de um cachorro e um macaco (hachurados pelos autores deste artigo em vermelho), que simbolicamente indicam a importância que a anatomia animal ainda desempenhava no estudo da anatomia humana. O macaco representava, ainda, um antigo símbolo da Medicina.

Figura 7. Frontispício da I edição do livro De Humani Corporis Fábrica.

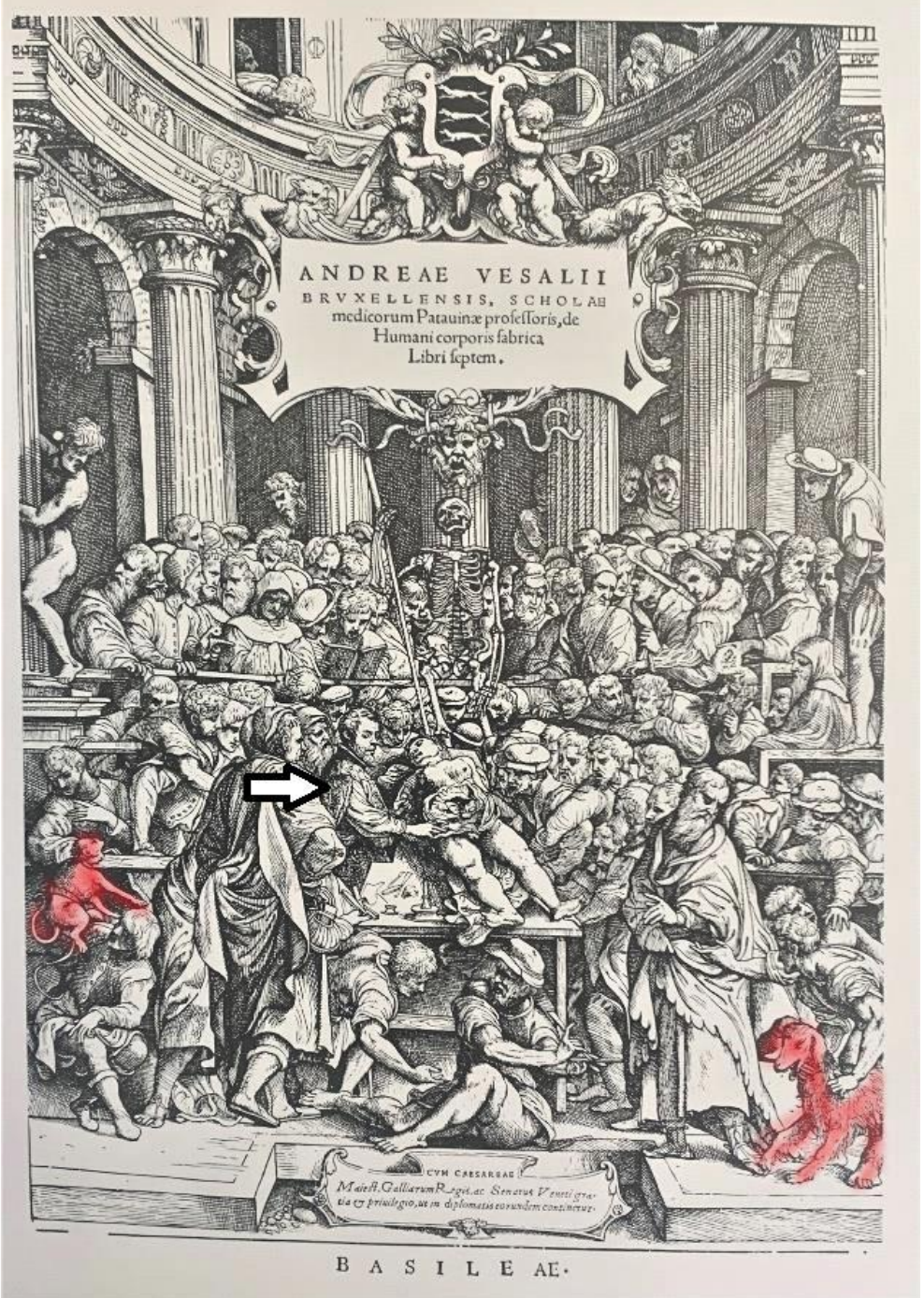

Fonte: Modificado de Saunders e O’Malley (2002). 
Na figura 8, compara-se o crânio humano com o de um canino. Vesalius contesta, então, a afirmação de Galeno que as suturas pré-maxilares existiriam no homem.

Figura 8. Xilogravura evidenciando a anatomia da cabeça humana e de canino.

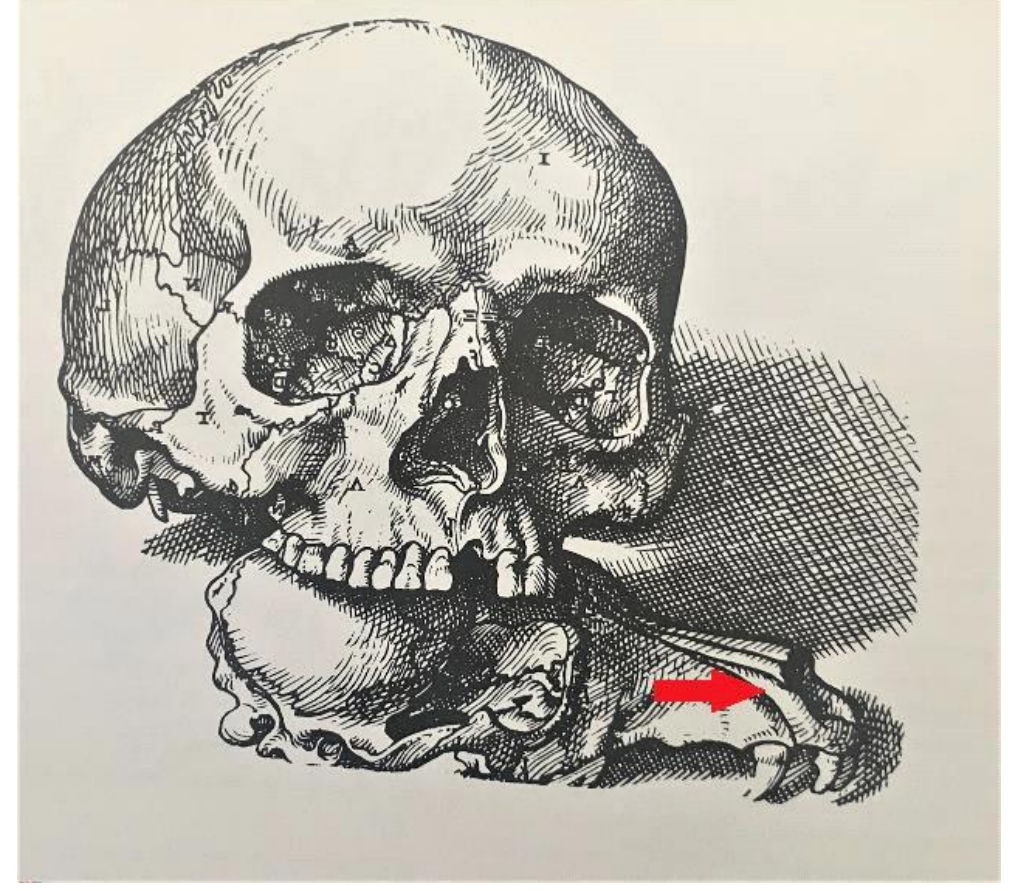

Fonte: Modificado de Saunders e O’’Malley (2002).

A figura 9 mostra, em A e B o aparelho hioide visto anteriormente (A) e posteriormente (B). A presença de ossículos na topografia do ligamento estilo-hioide, embora possam ser encontrados no homem, são característicos dos cães, embora Vesalius descreva no texto como sendo humanos. Em C, Vesalius mostra o anel fibroso da origem da aorta (maior) e da "veia arterial" (tronco pulmonar). Em D, nota-se o os cordis, presente nos ruminantes. Novamente, ele discorda de Galeno afirmando que este osso cardíaco inexiste em humanos. 
Figura 9. Xilogravuras evidenciando em A e B) Aparelho hioide, C) Anéis fibrosos da aorta em tronco pulmonar, D) Os cordis.

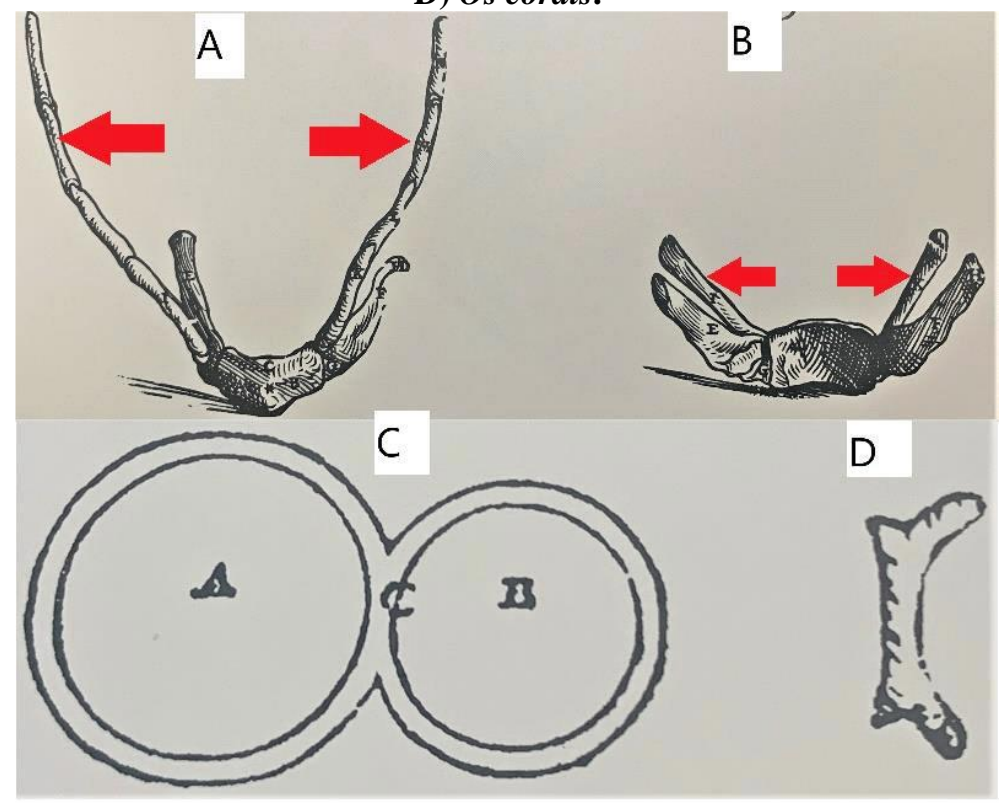

Fonte: Modificado de Saunders e O’Malley (2002).

A figura 10 evidencia o músculo coanoide ou retrator do bulbo ocular (em vermelho), presente nos ruminantes e inexistente no homem. Vesalius provavelmente confundiu a fáscia bulbar com este músculo.

Figura 10. Xilogravuras evidenciando a anatomia do olho.

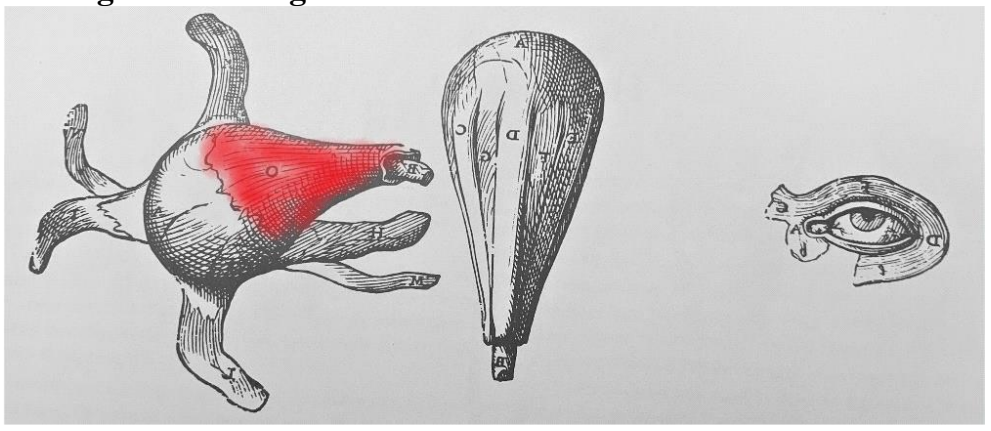

Fonte: Modificado de Saunders e O’Malley (2002).

A figura 11 representa uma "tábua de vivissecção", utilizada por Vesalius em seus experimentos de fisiologia, baseado nos conhecimentos de Galeno. Em A, observa-se o animal posicionado na mesa; em B uma broca primitiva, em C, o instrumental anatômico utilizado na tábua. 
Figura 11. Xilogravuras evidenciando a tábua de vivissecção. A) Posicionamento do animal. B) Broca primitiva. C) Instrumental para dissecação.

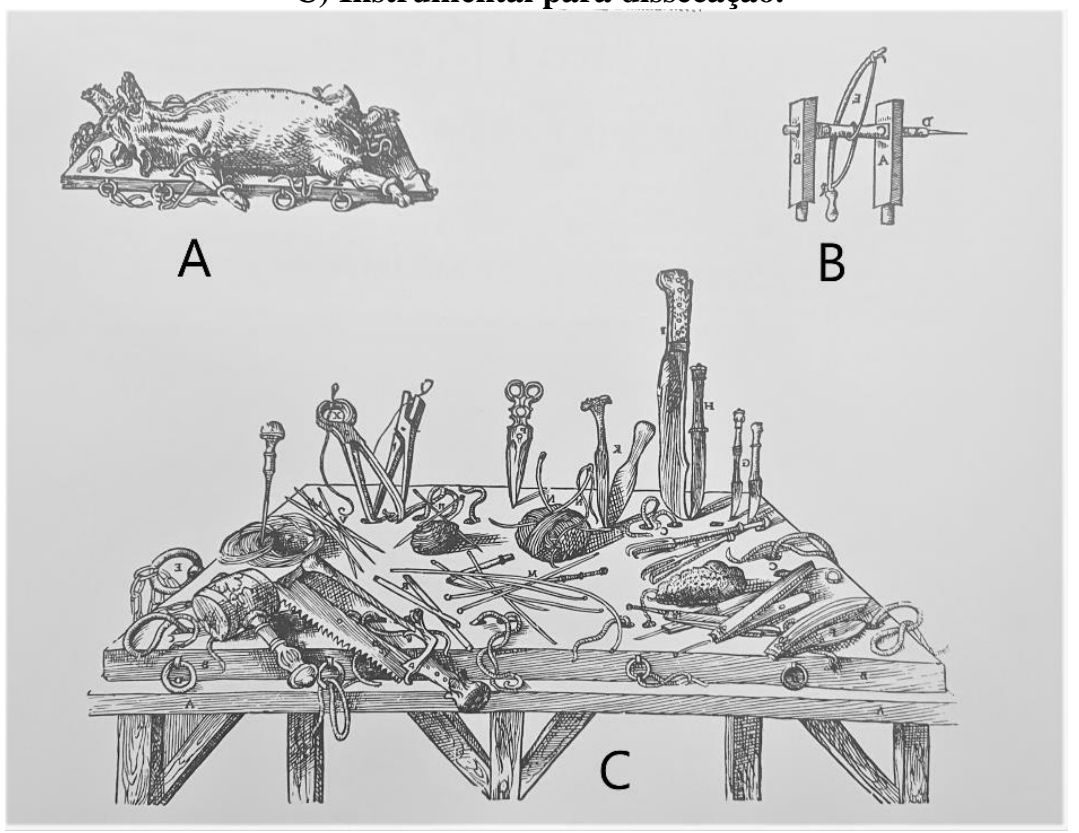

Fonte: Modificado de Saunders e O’Malley (2002).

Na figura 12, observam-se imagens da anatomia topográfica de músculos esqueléticos. Vesalius contestava os trabalhos de Galeno ao incluir estruturas animais inexistentes no homem. Em A, Galeno afirmava haver um "panículo carnoso" infiltrando a fáscia profunda. Vesalius afirmou que este panículo inexistia no homem, com exceção do platisma e dos músculos da expressão facial (em azul). Em B, Vesalius demonstra como seria se o músculo reto abdominal se ele se prologasse até a primeira costela (em amarelo), e em $\mathrm{C}$, como seria se o músculo escaleno anterior se prolongasse além da primeira costela (em vermelho).

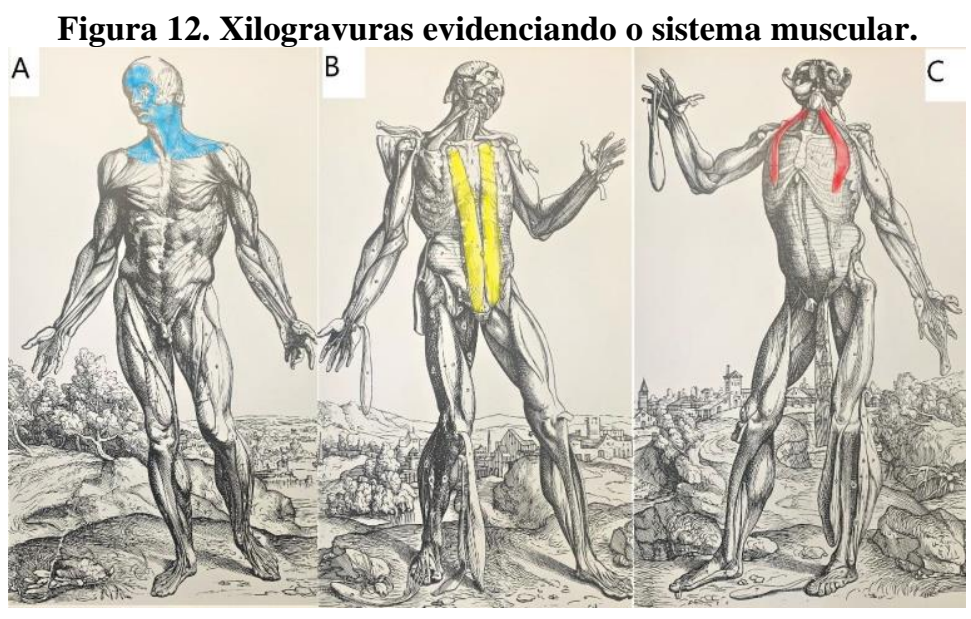

Fonte: Modificado de Saunders e O’Malley (2002). 
A Figura 13 evidencia o sistema arterial (A) e o venoso (B). A1 e B1 são detalhes de A e B. Em A1, o círculo vermelho mostra a origem dos vasos do arco da aorta que, de maneira semelhante aos estudos de da Vinci, foi baseada principalmente no padrão dos macacos. As setas pretas indicam artérias cervicais inferiores proeminentes, mais evidentes em cães. As setas azuis indicam artérias torácicas laterais volumosas, padrão este típico do cão e do porco. Em B1, o círculo preto indica as tributárias da veia cava (superior) que exibem um padrão animal. Conforme dito anteriormente, a veia cava constituía um único vaso, sendo o átrio direito considerado uma veia. As veias jugulares externas (setas vermelhas) eram retratadas mais calibrosas que as internas (setas verdes), padrão típico dos cães.

É importante lembrar que na época de Vesalius as veias eram consideradas mais importantes que as artérias, porque nelas se realizavam as sangrias, uma das poucas opções terapêuticas disponíveis naquele período.

Figura 13. Xilogravuras. A) artérias. B) veias. A1 e B1) Pormenores de A e B, respectivamente.
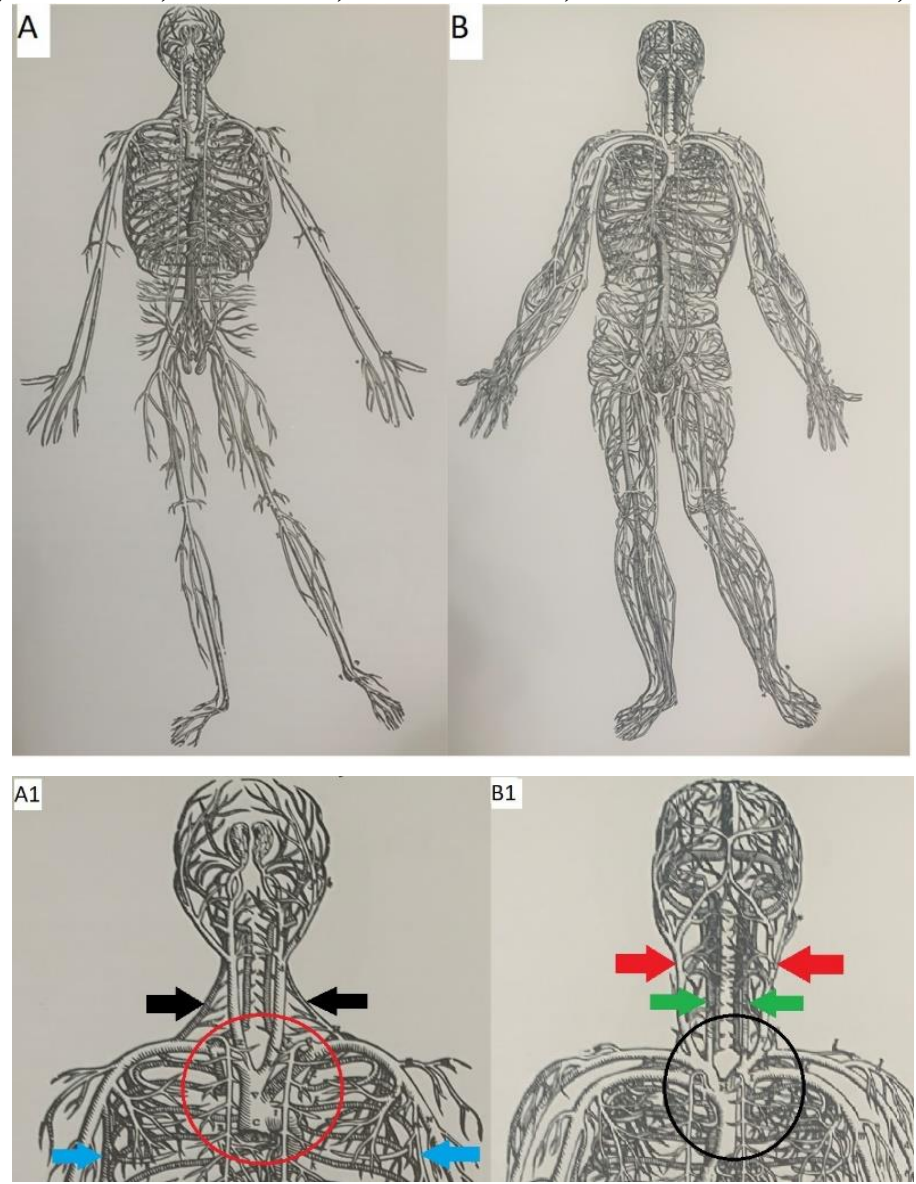

Fonte: Modificado de Saunders e O’’Malley (2002). 
Na figura 14, tem-se o sistema circulatório. Baseado na anatomia animal, Vesalius representa a veia porta com cinco ramos, ao invés dos habituais dois ramos do ser humano. Em B, ele faz um estudo da junção das veias jugulares e subclávias com a veia cava (superior), das quais nenhuma parece ocorrer no homem, porém semelhantes às variações encontradas em macacos e ungulados. Em $\mathrm{C}$, nota-se a inversão das veias renais, sendo a veia esquerda localizada inferiormente à direita.

Figura 14. Xilogravuras. A) sistema porta hepático. B) Variação na ramificação das veias do pescoço. C) Veia cava inferior e suas tributárias.

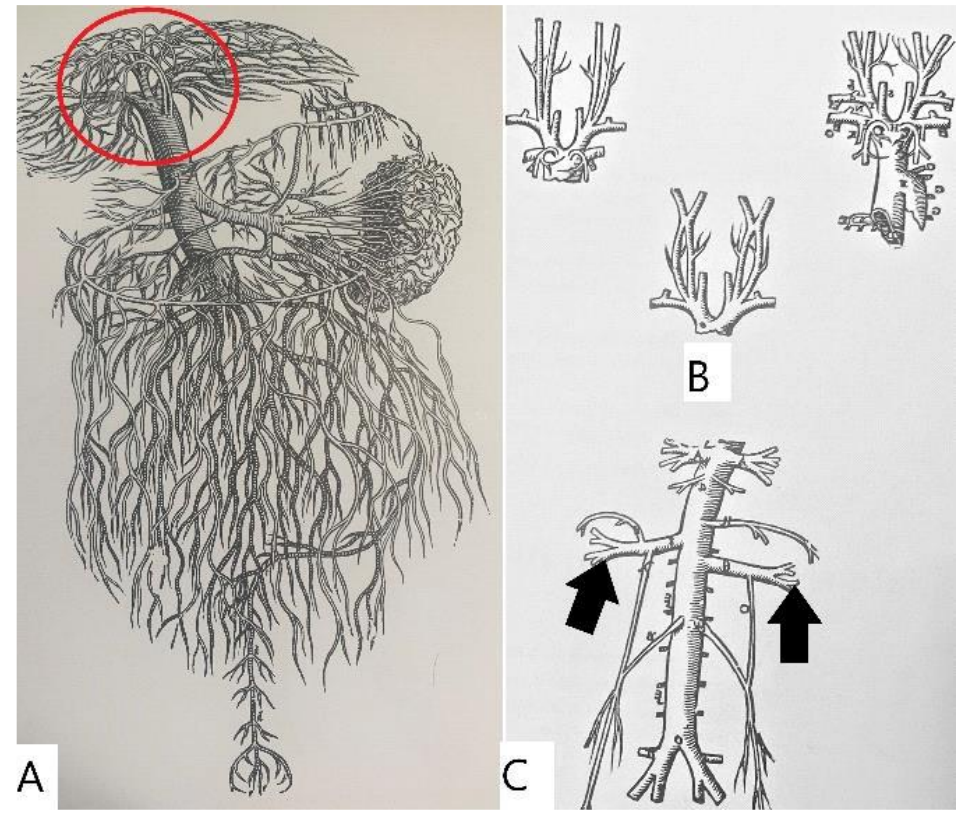

Fonte: Modificado de Saunders e O’Malley (2002).

A figura 15 evidencia o sistema urogenital masculino. Em A, novamente nota-se o rim direito posicionado superiormente ao esquerdo (setas vermelhas). Em B, notar a ausência das glândulas (vesículas) seminais; Vesalius deve ter se baseado na anatomia do cão, animal que não possui estas glândulas anexas. Também Vesalius comparou o útero humano (seta), com o de vaca em D e de cadela em E. 
Figura 15. A e B) Xilogravuras do aparelho urogenital masculino. A. Vista anterior. B. Vista posterior. C, D e E) Xilogravuras do sistema urogenital feminino.
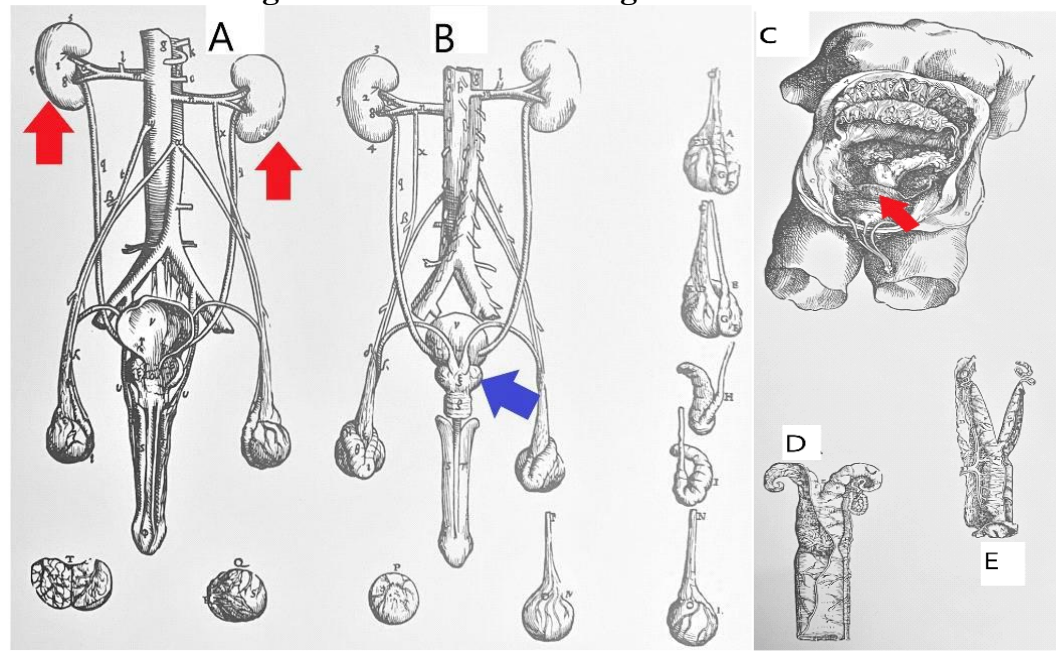

Fonte: Modificado de Saunders e O’Malley (2002).

Por fim, a figura 16 representa em A que na primeira edição de Fabrica Vesalius utilizou a placenta zonária da cadela associada ao feto humano. Em B, três anos depois, na segunda edição do livro, ele corrige o erro e representa o feto humano com a placenta discoidal, apresentando o argumento de que ele não havia tido acesso à placenta humana durante a confecção da primeira edição. Ele ainda faz a comparação entre os três tipos de placentas: discoidal dos primatas humanos e nãohumanos (C1), cotiledonária dos ruminantes (C2) e zonária dos carnívoros (C3), ilustrando pela primeira vez as diferenças anatômicas entre elas.

Figura 16. Xilogravuras: A) Placentação zonaria. B) Placentação discoidal. C) Comparação entre as placentas humana, bovina e canina.

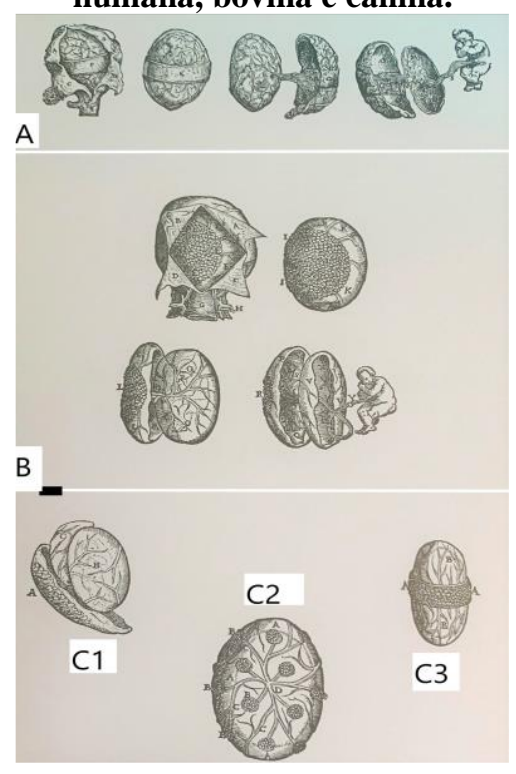

Fonte: Modificado de Saunders e O’Malley (2002). 
É importante lembrar que Galeno, o "príncipe dos médicos”, teve sua obra considerada imutável por séculos, dentre as quais o tratado De Anatomicis Administratiobus, sobre procedimentos em anatomia. Entretanto, é sabido que Galeno não dissecou cadáveres humanos, visto que este procedimento era proibido em seu tempo. Por isso, ele reconheceu as similaridades das estruturas anatômicas de diversos animais (em especial os macacos e os bovinos) e o homem, e inferiu os seus achados ao ser humano. Tais dados de anatomia foram considerados verdades absolutas, de forma que um de seus mais ardentes devotos o médico e filósofo francês Jacobus Sylvius (1478-1555) afirmava que "qualquer estrutura encontrada no homem contemporâneo cuja descrição divergisse daquela de Galeno seria apenas o resultado de posterior decadência e degeneração da espécie humana"17.

Assim, esta pesquisa corrobora ao fato de que tanto Da Vinci quanto Vesalius dificilmente poderiam estar livres da influência de Galeno, tanto na anatomia quanto na fisiologia. Os resultados deste trabalho mostram que muitos aspectos da anatomia animal foram incorporados ao estudo da anatomia humana, embora, principalmente Vesalius questionasse seriamente alguns achados através de suas dissecações. Portanto, durante a Idade Média, todo o conhecimento da anatomia humana do mundo ocidental estava baseado no estudo dos diferentes mamíferos, resultante dos trabalhos de Galeno, que não só os utilizava para fins de comparação, mas como substituto para o estudo da anatomia do homem visto a proibição vigente da disseção cadavérica humana até então ${ }^{18}$.

Com o surgimento das universidades de Bolonha (1158), Oxford (1167), Montpelier (1881) e Pádua (1222), a Igreja Católica foi lentamente permitindo a dissecação de cadáveres humanos, embora em 1299 o papa Bonifácio VIII tenha emitido a bula “De sepolturis”, que proibia a manipulação de mortos em batalha e sua redução a ossos para fins de transporte, estendendo esta bula para as dissecações anatômicas. Mesmo assim, isto não impediu as universidades de dissecarem cadáveres, geralmente de criminosos executados, uma fonte restrita portanto. Além disso, a inexistência de fixadores químicos dificultava a dissecação em vista da rápida decomposição do corpo. As dissecações eram geralmente realizadas no inverno, onde as baixas temperaturas conservavam os cadáveres por um tempo maior.

\footnotetext{
${ }^{17}$ Charles Singer, Rachel Lewinsohn. Uma breve história da anatomia e fisiologia desde os gregos até Harvey. (Unicamp: Cidade Universitária, 1996).

18 Christopher E. Cosans, Michael Frampton. History of Comparative Anatomy. eLS (2015):1-8, Doi: https://doi.org/10.1002/9780470015902.a0003085.pub2
} 
As dissecações públicas começaram a se tornar populares, principalmente na Itália; entretanto, na maioria das vezes o professor somente lia os escritos de Galeno, enquanto os "cirurgiões-barbeiros" (geralmente pessoas iletradas) faziam as incisões ${ }^{19}$. Além disso, não se realizavam ilustrações baseadas nos achados visualizados (figura 17, comparar com a figura 7). Vesalius foi considerado o primeiro a descer da cátedra e realizar suas próprias dissecações, o que lhe permitiu a liberdade de descrever o que observou durante a prática.

Figura 17. Lição de Anatomia, de Joannes de Kethan, Fasciculo de Medicina, 1494.

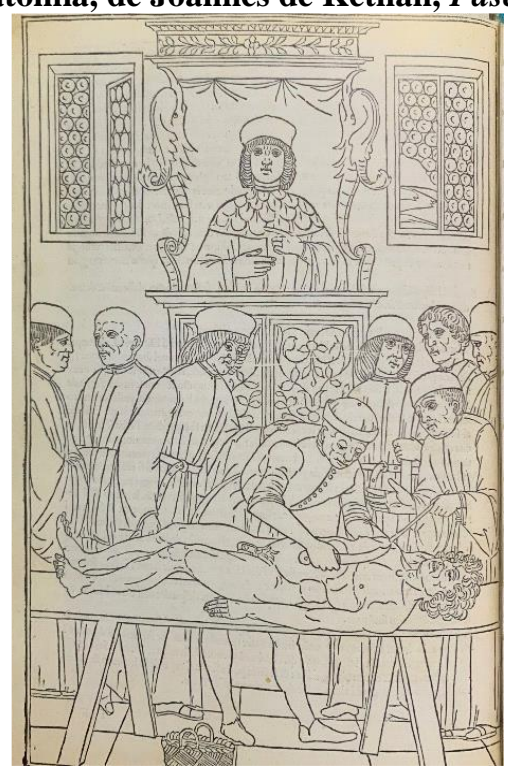

Fonte: Rifkin, Ackerman e Folkenberg (2006).

As obras de da Vinci, e depois, de Vesalius abriram caminho para o estudo científico baseado em observação e experimentação, enquanto os estudos em animais foram transportados para a Fisiologia e a Medicina Veterinária propriamente dita. Dentre os diversos critérios para comparar as estruturas anatômicas em diferentes espécies, têm-se a homologia e a analogia como fundamentais no que se referem a conceitos básicos da Anatomia Comparativa. A homologia é o estudo da identidade dos órgãos que possuem a mesma origem embrionária, a mesma estrutura e a mesma localização em diferentes animais, independentemente das variações de forma e função. Já a analogia é o estudo da semelhança funcional de órgãos em diferentes espécies de animais, mesmo com desenvolvimento embrionário e estruturas diferentes. Assim, esses conceitos são importantes para entender as variações anatômicas e a interpretação morfológica dessas variações.

\footnotetext{
${ }^{19}$ Benjamin Rifkin et al. Human anatomy: Depicting the body from the Renaissance to today. (Londres: Thames \& Hudson, 2006).
} 
Portanto, acredita-se que o presente manuscrito colabore com questões relacionadas à construção do conhecimento médico e artístico, abordando os primórdios das descobertas sobre o corpo que engloba, historicamente, alguns erros tanto de conceito como de técnica anatômica. Finalmente, acredita-se que usar a história da ciência como uma ferramenta didática seja importante para instigar o ensino-aprendizado sobre as estruturas anatômicas nos dias de hoje. E, embora a Anatomia Comparativa como ciência feita pela técnica da dissecação espécie-específica nem sempre tenha existido da forma como é atualmente estudada, sua evolução culminou com vastas mudanças de prioridades científicas, eventos históricos e socioculturais, bastante influenciadas pela anatomia artística que representa visualmente a morfologia externa e interna do corpo.

\section{Conclusão}

Conclui-se que o estudo da anatomia animal influenciou sobremaneira os primórdios do estudo da anatomia humana; pois, sendo a espécie humana apenas uma dentre as numerosas espécies animais, estabelecer comparações entre características anatômicas do homem e da mulher com aquelas correspondentes de animais foi importante durante muitos anos. Seus efeitos (contributivos e deletérios) para a Educação Médica ao longo dos séculos podem ser esclarecidos através da Arte numa profunda interação entre obras científicas e artísticas.

\section{Referências}

Bauer, Martin W., George Gaskell. Pesquisa qualitativa com texto, imagem e som: um manual prático. Petrópolis: Editora Vozes Limitada, 2017.

Conner, Annastasia. "Galen's Analogy: Animal Experimentation and Anatomy in the Second Century CE." Anthós 8, 1 (2017): 9, DOI: https://doi.org/10.15760/anthos.2017.118.

Cosans, Christopher E., and Michael Frampton. History of Comparative Anatomy. eLS. 2015:1-8, DOI: https://doi.org/10.1002/9780470015902.a0003085.pub2.

Di Dio, Liberato JA. Tratado de anatomia aplicada. São Paulo: Poluss, 1998.

Domingo, Inés, Pilar García-Argüelles, Jordi Nadal, Josep Ma Fullola, José L. Lerma, and Miriam Cabrelles. "Humanizing european paleolithic art: A new visual evidence of human/bird interactions at L'Hort de la Boquera site (Margalef de Montsant, Tarragona, Spain)." L'Anthropologie 123, 1 (2019): 1-18, DOI: https://doi.org/10.1016/j.anthro.2019.01.001.

Garate, Diego, Olivia Rivero, Joseba Ríos-Garaizar, Martin Arriolabengoa, Ma Ángeles Medina-Alcaide, Juan Francisco Ruiz-López, Iñaki Intxaurbe, Sergio Salazar, and Iñaki Libano. "The cave of Atxurra: a new major Magdalenian rock art sanctuary in Northern Spain." Journal of Archaeological Science: Reports 29 (2020): 102120, DOI: https://doi.org/10.1016/j.jasrep.2019.102120. 
Ghosh, Sanjib Kumar. "Human cadaveric dissection: a historical account from ancient Greece to the modern era." Anatomy \& cell biology 48, $3 \quad$ (2015): 153, DOI: http://dx.doi.org/10.5115/acb.2015.48.3.153.

Mitrousias, Vasileios, Kyriaki Baxevanidou, and Aristeidis Zibis. "Art \& anatomy: an everlasting relationship creating new insights in teaching surface anatomy." MedEdPublish 9 (2020), DOI: https://doi.org/10.15694/mep.2020.000023.1.

OMalley, Charles Donald and John Bertrand Sanders. "Andreas Vesalius de Bruxelas, De humani corporis fabrica. Epitome. Tabulae sex: ilustrações e comentários dos trabalhos anatômicos." Campinas: Editora Unicamp, 2002.

O'Malley, Charles Donald, John Bertrand de Cusance Morant Saunders, and John Bertrand de Cusance Morant Saunders. Leonardo da Vinci on the human body: The anatomical, physiological, and embryological drawings of Leonardo da Vinci: with translations, emendations and a biographical introduction. Bexley: Gramercy Books, 1982.

Ortale, José Roberto. "A importância da anatomia na formação do médico." Títulos não-correntes 8, $1 / 2$ (2012), DOI: http://periodicos.puc-campinas.edu.br/seer/index.php/bioikos/article/viewFile/971/948.

Park, Won Jin, Soo Jung Jung, Yu Ran Heo, and Jae Ho Lee. "Anatomy in Michelangelo Art." Keimyung Medical Journal 37, 2 (2018): 76-81, DOI: http://doi.org/10.0000/kmj.2018.37.2.76.

Rifkin, Benjamin A., Michael J. Ackerman, Judith Folkenberg. Human anatomy: Depicting the body from the Renaissance to today. Londres: Thames \& Hudson, 2006.

Singer, Charles, Rachel Lewinsohn. Uma breve história da anatomia e fisiologia desde os gregos até Harvey. UNICAMP: Cidade Universitária, 1996.

Zöllner, Frank, Johannes Nathan. Leonardo da Vinci, 1452-1519: The Complete Paintings and Drawings, catalogue raisonné. Colônia: Taschen, 2015. 